\title{
Sciopemyia vattierae (Le Pont \& Desjeux, 1992) (Diptera, Psychodidae, Phlebotominae): new record from Acre state, Brazil
}

\author{
Márcia Moreira de Ávila ${ }^{1}$, Andreia Fernandes Brilhante ${ }^{2}$, Eunice Aparecida Bianchi Galati ${ }^{3}$, \\ Acigelda da Silva Cardoso ${ }^{4}$, Reginaldo Peçanha Brazil ${ }^{5}$
}

\begin{abstract}
1 Federal Institute of Acre, Av. Brasil, 920, Xavier Maia, Rio Branco, AC, Brazil. 2 Federal University of Acre, Rodovia BR 364, Km 04, s/n, Distrito Industrial, Rio Branco, AC, Brazil. 3 Faculty of Public Health, Av. Dr. Arnaldo, 715, Pacaembu, University of São Paulo, SP, Brazil. 4 Rio Branco City Hall, Entomological Surveillance Service, Avenida Ceará, 3.335, Jardim Nazle, Rio Branco, AC, Brazil. 5 Oswaldo Cruz Institute, IOC/FIOCRUZ, Av. Brasil, 4365, Manguinhos, Rio de Janeiro, RJ, Brazil.
\end{abstract}

Corresponding author: Márcia Moreira de Ávila, marcia.avila@ifac.edu.br

\begin{abstract}
Sciopemyia vattierae (Le Pont \& Desjeux, 1992) (Diptera, Psychodidae, Phlebotominae) is reported for the first time from Brazil. Five male and 4 female specimens were collected using HP light traps set up in a rural area of the municipality of Rio Branco, state of Acre, Brazil, from December 2014 to January 2016. This species was previously known only in Bolivia, Peru, and Colombia. Our new record extends the known distribution of S. vattierae to the Amazonian region of Acre and represents a new national record for Brazil.
\end{abstract}

Key words

Sand flies; geographic distribution; Amazonia; South America.

Academic editor: Kirstern Lica Follmann Haseyama | Received 1 February 2018 | Accepted 11 June 2018 | Published 13 July 2018

Citation: Ávila MM, Brilhante AF, Galati EAB, Cardoso AS, Brazil RP (2018) Sciopemyia vattierae (Le Pont \& Desjeux, 1992) (Diptera, Psychodidae, Phlebotominae): new record from Acre state, Brazil. Check List 14 (4): 585-589. https://doi.org/10.15560/14.4.585

\section{Introduction}

Phlebotomine sand flies are dipterans of public health importance for transmitting parasites of the genus Leishmania (Ross, 1903), Bartonella, Strong et al. 1915, and arboviruses. It is estimated that there are about 530 species of Phlebotominae in the Americas (Shimabukuro et al. 2017), and the Amazonia biome contributes the greatest richness and diversity of taxa. In the state of Acre, 83 species of sand flies have been reported, which corresponds to $30 \%$ of the species found in Brazil, according to the taxonomic catalog of the fauna of Brazil (Shimabukuro et al. 2018).
The Amazon region is considered endemic for American Cutaneous Leishmaniasis (ACL), and studies have been concentrated on the vectorial role of phlebotomine sand flies. However, there are still incipient studies on the ecological and biological aspects of the phlebotomine fauna in the state of Acre, which is rich and diverse with recent descriptions and new records of species (Tojal et al. 2006, Teles et al. 2013, 2016, Araújo-Pereira et al. 2014, 2017, Brilhante et al. 2017). The present study had, as its objective, to report the first record of Sciopemyia vattierae (Le Pont \& Desjeux, 1992) in Acre and Brazil, which increases the number of species for this state and for Brazil. 


\section{Methods}

The specimens of phlebotomine sand flies were collected between December 2014 and January 2016 in the municipality of Rio Branco, state of Acre, in a rural area and urban forest of the municipality $\left(09^{\circ} 59^{\prime} 11^{\prime \prime} \mathrm{S}\right.$, $\left.067^{\circ} 49^{\prime} 52^{\prime \prime} \mathrm{W}\right)$ using $6 \mathrm{HP}$ light traps installed at 18:00 and collected at 6:00 once a month during the study period; more details are available at Ávila et al. (2018). The specimens were processed according to Forattini (1973) and identified according to the taxonomic key proposed by Galati (2003).

The specimens were collected under a permanent license number 32669-4 to collect zoological material granted to Reginaldo P. Brazil by the Ministério do Meio Ambiente (MMA), Instituto Brasileiro do Meio Ambiente e dos Recursos Naturais Renováveis (IBAMA), Instituto Chico Mendes de Conservação da Biodiversidade (ICMBio), and Sistema de Autorização e Informação em Biodiversidade (SISBIO).

\section{Results}

New records. Brazil: Acre: Rio Branco: roadway Transacreana, hen house $\left(09^{\circ} 59^{\prime} 46.8^{\prime \prime} \mathrm{S}, 067^{\circ} 58^{\prime} 51.7^{\prime \prime} \mathrm{W}\right)$, Márcia Moreira de Ávila and Andreia Fernandes Brilhante, collectors, 9 February 2015 (first record) 1 individual (male); Brazil: Acre: Rio Branco: roadway Transacreana, Riozinho do Rola ( $\left.10^{\circ} 05^{\prime} 03.5^{\prime \prime} \mathrm{S}, 067^{\circ} 53^{\prime} 54.3^{\prime \prime} \mathrm{W}\right)$, Márcia Moreira de Ávila and Andreia Fernandes Brilhante, collectors, 15 June 2015 (first record) 2 individuals (male and female); Brazil: Acre: Rio Branco: roadway Transacreana, hen house (0959'46.8' S, 06758'51.7" W), Márcia Moreira de Ávila and Andreia Fernandes Brilhante, collectors, 5 July 2015, 1 individual (female); Brazil: Acre: Rio Branco: roadway Transacreana, forest area (0959'49.8" S, 06758'50.7" W), Márcia Moreira de Ávila and Andreia Fernandes Brilhante, collectors, 10 August 2015, 1 individual (male); Brazil: Acre: Rio Branco: roadway Transacreana, forest area (0959'49.8" S, 06758'50.7" W), Márcia Moreira de Ávila and Andreia Fernandes Brilhante, collectors, 15 September 2015, 1 individual (male); Brazil: Acre: Rio Branco: urban area, Horto Florestal (0956'51.7" S, 06749'42.8" W), Márcia Moreira de Ávila, collector, 7 October 2015, 1 individual (female); Brazil: Acre: Rio Branco: urban area, Horto Florestal (0956'51.7" S, 06749'42.8" W), Márcia Moreira de Ávila, collector, 16 December 2015, 1 individual (female); Brazil: Acre: Rio Branco: urban area, Horto Florestal (0956'51.7" S, 06749'42.8" W), Márcia Moreira de Ávila, collector, 20 January 2016, 1 individual (male).

A total of 2,517 phlebotomine sand flies were collected. The fauna that compose 43 species and their ecological analyses are published in Ávila et al. (2018). Among those phlebotomine sand flies, 5 males and 4 females of Sciopemyia vattierae were identified. They were collected in rural areas $\left(09^{\circ} 59^{\prime} 49.8^{\prime \prime} \mathrm{S}, 067^{\circ} 58^{\prime} 50.7^{\prime \prime} \mathrm{W}\right)$ and urban forest (09 56'51.7" S, 06749'42.8' W) (Fig. 1). The slides of 4 sand fly specimens were deposited under the number E-15630, E-15631 (female), E15632 and E-15633 (male) in the laboratory of phlebotomine sand flies of the Faculty of Public Health of the University of São Paulo. The other 5 specimens are in the private collection of the first author.

Identification. The genus Sciopemyia Barretto, 1962 is characterized by antennal flagellomeres relatively long with simple ascoids. Palpus segment V shorter or subequal to palpus segment III. Female cibarium with 4 horizontal teeth, with the inner pair separated by a relatively wide gap. Male genitalia: style with 4 spines and no subterminal seta. According to Galati (2003, 2016), the genus Sciopemyia includes 8 species: S. fluviatilis (Floch \& Abonnenc, 1944); S. microps (Mangabeira, 1942); S. nematoducta (Young \& Arias, 1984); S. pennyi (Arias \& Freitas, 1981); S. preclara (Young \& Arias, 1984); S. servulolimai (Damasceno \& Causey, 1945); $S$. sordellii (Shannon \& Del Ponte, 1927); and S. vattierae. Among these species, $S$. vattierae is morphologically most similar to $S$. sordellii.

The presence of papilla on the flagellomere III distinguishes $S$. vattierae and $S$. sordellii from the other species of the genus, in which the papilla on the flagellomere III is absent. The distinction between males of these 2 species was based on morphometric characters (lengths of flegellomere I and aedeagal ducts) (Fig. 2A), and morphological characteristics of the females: $S$. vattierae presents the terminal knob clearly separated from the spermatheca, and it is sessile in S. sordellii (Fig. 2B).

\section{Discussion}

Species of the genus Sciopemyia are widely distributed in Latin America, but most are reported from Brazil, such as $S$. microps, $S$. nematoducta, $S$. servulolimai, and $S$. pennyi. The other species have been reported from other countries, such as $S$. fluviatilis from French Guiana, $S$. preclara from Colombia and Peru, and S. sordelli from Argentina (Shimabukuro et al. 2017).

Sciopemyia vattierae was described by Le Pont and Desjeux (1992) from specimens collected in the Bolivian Amazon rainforest of Yucumo (Bolivia). The female was redescribed by Bejarano et al. (2006) from specimens collected in La Macarena, Meta Department, Colombia. Currently, this species' distribution includes areas of tropical and humid forests of Bolivia, Peru, and Colombia, and the localities in which this species has been recorded suggests that its distribution is cis-Andean (Le Pont and Desjeux 1992, Ogusuku et al. 2001, Bejarano et al. 2006, Cabrera et al. 2009, Trujillo et al. 2013).

Species of this genus feed on amphibians and coldblooded animals, Sciopemyia sordellii naturally infects frogs with parasites of the genus Trypanosoma (Ferreira et al. 2008). Regarding the parasites of the genus Leishmania, S. sordellii was detected with subgenus 


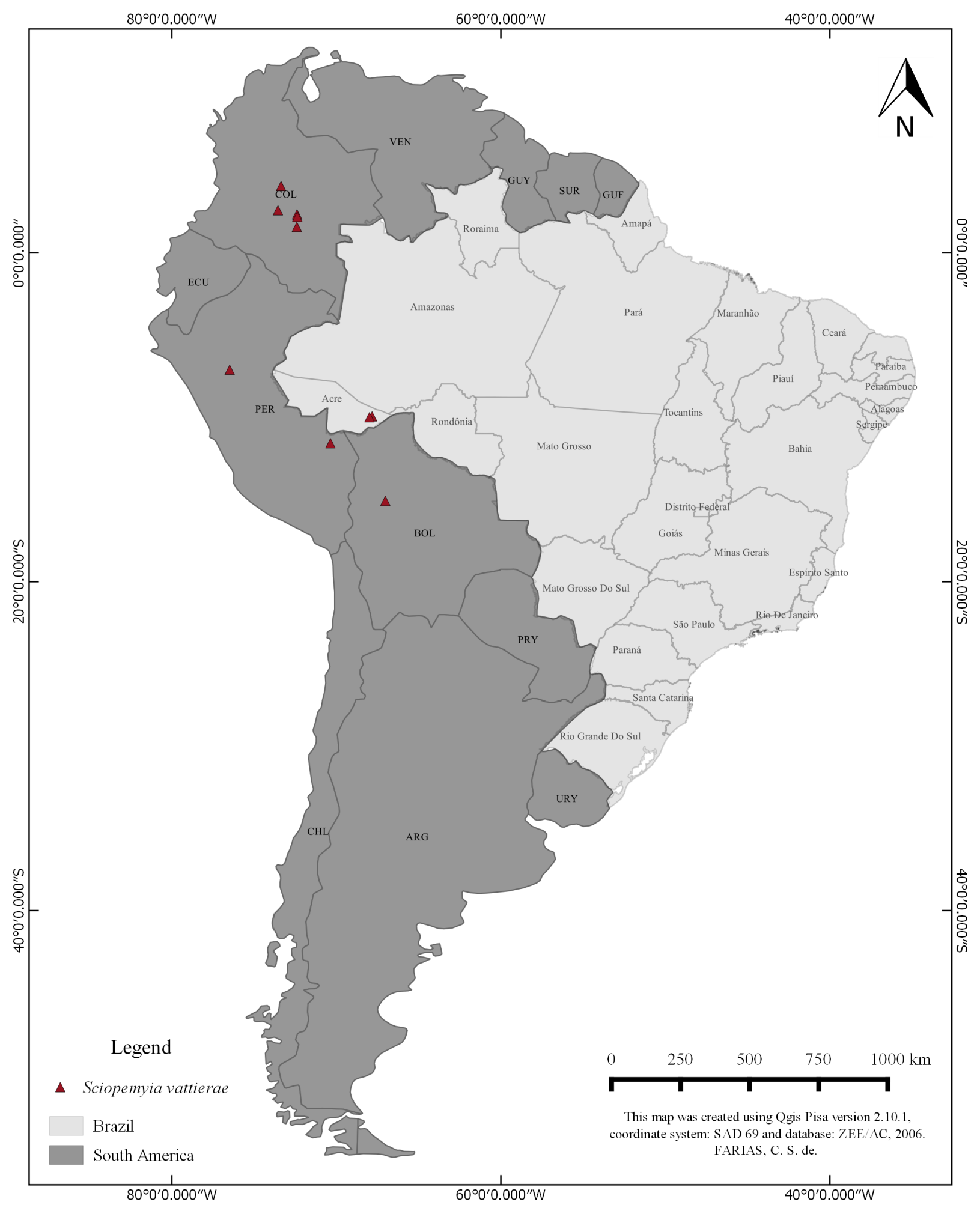

Figure 1. Map of the geographical distribution of Sciopemyia vattierae in South America.

Leishmania in cave areas of Minas Gerais state (Carvalho et al. 2017).

We collected specimens of $S$. vattierae in a forested area near the peridomicile. In faunal surveys in Brazil, the species of this genus are generally collected in rural forest and anthropic environments (Gomes et al. 2009, Alves et al. 2012, Ramos et al. 2014). However, in com- parison to other genera and species of sand flies, our study and that of Ávila et al. 2018 show low population densities of $S$. vattierae.

Thus, with our new records, we see an increase in the geographical distribution of $S$. vattiearae in South America (Fig. 1), as well as in the number of species of sand flies in Brazil and Acre. 


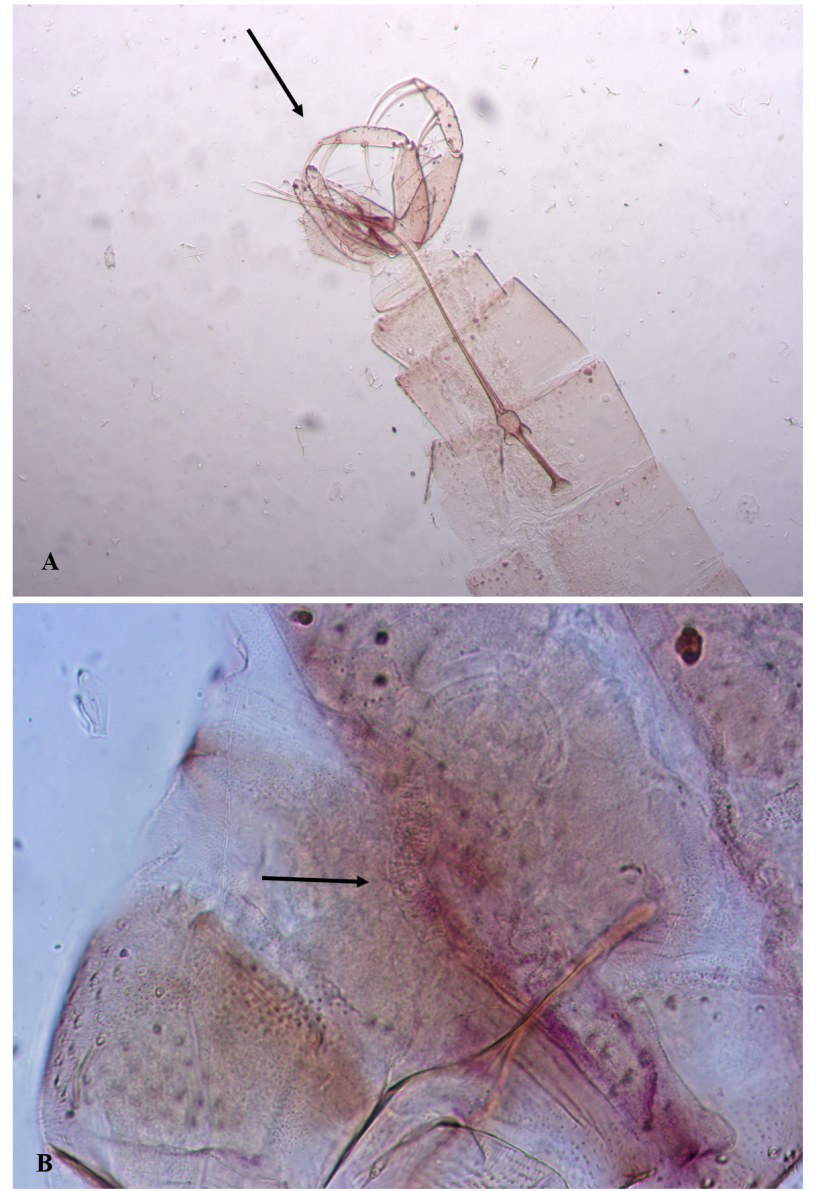

Figure 2. Specimens of Sciopemyia vattierae collected in Rio Branco, Acre, Brazil. A. Terminalia of the male, $100 \mu \mathrm{m}$. B. spermatheca of the female, $10 \mu \mathrm{m}$. The arrows indicate the genital structures.

\section{Acknowledgements}

We thank the Municipal Government of Rio Branco, the Service of Entomology and Chemical Control. Our thanks also go to Mr Janis Lunier de Souza for support with field collections, to Mr Cleilton Sampaio for preparing the map, and to the Federal Institute of Acre and the Oswaldo Cruz Institute through the Cooperation Instrument 004/2012 IFAC/IOC. We also thank the Fundação de Amparo à Pesquisa do Estado do Acre (Grant Agreement Number PPSUS No. 001/2015) for their financial support.

\section{Authors' Contributions}

MMA and RPB designed the study. AFB, MMA, ASC and EABG conducted the field work. MMA, AFB, RPB and $\mathrm{EABG}$ prepared the materials and identified the phlebotomine specimens. MMA, AFB and RPB wrote the text.

\section{References}

Alves VR, Freitas RA, Santos FL, Oliveira AFJ, Barret TV, Shimabukuro PHF (2012). Sand flies (Diptera, Psychodidae, Phlebotominae) from central Amazonia and four new records for the Amazonas state, Brazil. Revista Brasileira de Entomologia. 56 (2): 220-227.
https://doi.org/10.1590/S0085-56262012005000020

Ávila MM, Brilhante AF, Souza CF, Bevilacqua PD, Galati EAB, Brazil RP (2018). Ecology, feeding and natural infection by Leishmania spp. of phlebotomine sand flies in an area of high incidence of American tegumentary leishmaniasis in the municipality of Rio Branco, Acre, Brazil. Parasites \& Vectors 11: 64. https://doi. org/10.1186/s13071-018-2641-y

Araújo-Pereira T, Fuzari AA, Andrade Filho JD, Pita-Pereira D, Britto C, Brazil RP (2014). Sand fly fauna (Diptera: Psychodidae: Phlebotominae) in an area of leishmaniasis transmission in the municipality of Rio Branco, state of Acre, Brazil. Parasites \& Vectors 7: 360. https://doi.org/10.1186/1756-3305-7-360

Araújo-Pereira T, Pita-Pereira D, Boité MC, Melo M, Costa-Rego TA, Fuzari AA, Brazil RP, Britto C (2017). First description of Leishmania (Viannia) infection in Evandromyia saulensis, Pressatia sp. and Trichophoromyia auraensis (Psychodidae: Phlebotominae) in a transmission area of cutaneous leishmaniasis in Acre state, Amazon basin, Brazil. Memórias do Instituto Oswaldo Cruz 112 (1): 75-78. https://doi.org/10.1590/0074-02760160283

Bejarano EE, Duque P, Vélez ID (2006). Redescripción de la hembra de Lutzomyia vattierae (Diptera: Psychodidae, Phlebotominae) de la serranía de La Macarena, Colombia. Biomédica 26: 556-561.

Brilhante AF, Sábio PB, Galati EAB (2017). A new species of sand fly, Psathyromyia elizabethdorvalae sp. n. (Diptera: Psychodidae: Phlebotominae), from Brazil. Journal of Medical Entomology 54 (1): 76-81. doi: https://doi.org/10.1093/jme/tjw150

Cabrera O, Mosquera L, Santamaría E (2009). Flebótomos (Diptera: Psychodidae) del departamento de Guaviare, Colombia, con nuevos registros para el país. Biomédica 29: 73-86. https://doi. org/10.7705/biomedica.v29i1.43

Carvalho GM, Brazil RP, Rêgo FD, Ramos MC, Zenóbio AP, Andrade Filho JD (2017). Molecular detection of Leishmania DNA in wildcaught phlebotomine sand flies (Diptera: Psychodidae) from a cave in the state of Minas Gerais, Brazil. Journal of Medical Entomology 54 (1): 196-203. https://doi.org/10.1093/jme/tjw137

Ferreira RC, Souza AA, Freitas RA, Campaner M, Takata CSA, Barrett TV, Shaw JJ, Teixeira MMG (2008). A phylogenetic lineage of closely related trypanosomes (Trypanosomatidae, Kinetoplastida) of anurans and sand flies (Psychodidae, Diptera) sharing the same ecotopes in Brazilian Amazonia. Journal of Eukaryotic Microbiology 55 (5): 427-435. https://doi.org/10.1111/j.15507408.2008.00342.x

Forattini OP (1973). Entomologia Médica. Phlebotominae. Leishmanioses. Bartonelose. Edgard Blücher, São Paulo, 658 pp.

Galati EAB (2003). Morfologia e taxonomia: morfologia, terminologia de adultos e identificação dos táxons da América; ppin: Rangel EF and Lainson R (Eds). Flebotomíneos do Brasil. Editora Fiocruz, Rio de Janeiro, 53-175.

Galati EAB (2016). Bioecologia e identifcação de Phlebotominae. http://www.fsp.usp.br/ egalati/ApostilaPhlebotominae 2016 VOL_I.pdf. Accessed on: 2017-10-30.

Gomes LHM, Nery LCR, Pinheiro FG, Freitas RA, Franco AMR (2009). Fauna de flebotomíneos (Diptera: Psychodidae: Phlebotominae) em terra firme e planície fluvial na área de influência do gasoduto Coari-Manaus, Amazonas, Brasil. Acta Amazonica 39 (1): 233-239. https://doi.org/10.1590/S0044-59672009000100027

Le Pont F, Desjeux, P (1992). Phlébotomes de Bolivie. Description de Lutzomyia vattierae n. sp. et de la femelle de L. antezanai Le Pont, Dujardin et Desjeux, 1989 (Diptera, Psychodidae). Bulletin de la Societé entomologique de France 97: 263-268.

Ogusuku E, Guevara Z, Revilla L, Inga A, Perez, JE (2001). Descripción de Lutzomyia pisuquia sp. n. (Diptera:Psychodidae) y dos registros nuevos de Lutzomyia para el Perú. 2001. Revista Peruana de Entomología 42: 21-25.

Ramos WR, Medeiros JF, Julião GR, Ríos-Velásquez CM, Marialva EF, Desmouliére SJ, Luz SL, Pessoa FA (2014). Anthropic effects on sand fly (Diptera: Psychodidae) abundance and diversity in an Amazonian rural settlement, Brazil. Acta Tropica 139: 44-52. 
https://doi.org/10.1016/j.actatropica.2014.06.017

Shimabukuro PHF, Andrade AJ, Galati EAB (2017). Checklist of American sand flies (Diptera, Psychodidae, Phlebotominae): genera, species, and their distribution. ZooKeys 660: 67-106: https:// doi.org/10.3897/zookeys.660.10508. Accessed on 2017-8-12.

Shimabukuro PHF, Andrade AJ, Galati EAB (2018). Phlebotominae in Catálogo Taxonômico da Fauna do Brasil. PNUD. http://fauna.jbrj. gov.br/fauna/faunadobrasil/3297. Accessed on: 2018-5-25

Teles CBG, Freitas RA, Oliveira AFJ, Ogawa GM, Araújo EAC, Medeiros JF, Camargo LMA (2013). Description of a new phlebotomine species (Diptera: Psychodidae, Phlebotominae) and new records of sand flies from the state of Acre, northern Brazil. Zootaxa 3609 (1): 85-90. https://doi.org/10.11646/zootaxa.3609.1.6

Teles CBG, Santos APA, Freitas RA, Oliveira AFJ, Ogawa GM, Rodrigues MS, Pessoa FAC, Medeiros JF, Camargo LMA (2016).
Phlebotomine sandfly (Diptera: Psychodidae) diversity and their Leishmania DNA in a hot spot of American Cutaneous Leishmaniasis human cases along the Brazilian border with Peru and Bolivia. Memórias do Instituto Oswaldo Cruz 111 (7): 423-432 https://doi. org/10.1590/0074-02760160054

Tojal SAC, Cupolillo E, Volpini ÂC, Almeida R, Sierra Romero GA (2006). Species diversity causing human cutaneous leishmaniasis in Rio Branco, state of Acre, Brazil. Tropical Medicine \& International Health 11 (9): 1388-1398. http://doi.org/cckx76

Trujillo AV, Reina AEG, Orjuela AG, Suarez EP, Palomares JE, Alvarez LSB (2013). Seasonal variation and natural infection of Lutzomyia antunesi (Diptera: Psychodidae: Phlebotominae), an endemic species in the Orinoquia region of Colombia. Memórias do Instituto Oswaldo Cruz 108 (4): 463-469. https://doi.org/10.1590/S00740276108042013011 